\title{
Perceptions of the Comparative Safety of Different Forms of Marijuana Use Among the Adult US Population
}

\author{
Sodahm R. Yoo, $B A^{7}$, Camille Dollinger, $B A^{7}$, Marzieh Vali, $\mathrm{MS}^{7}$, Stacey Steigerwald, $\mathrm{MSSA}^{7}$, \\ Beth E. Cohen, MD MAS $S^{2,3}$, Julie H. Ishida, MD MAS ${ }^{2,4}$, and Salomeh Keyhani, MD MPH ${ }^{2,3}$ \\ ${ }^{1}$ Northern California Institute for Research and Education, San Francisco, CA, USA; ${ }^{2}$ Department of Medicine, University of California, San Francisco, \\ San Francisco, CA, USA; ${ }^{3}$ General Internal Medicine, San Francisco Veterans Administration, San Francisco, CA, USA; ${ }^{4}$ Nephrology, San Francisco \\ Veterans Administration, San Francisco, CA, USA.
}

J Gen Intern Med 34(4):504-6

DOI: $10.1007 / \mathrm{s} 11606-018-4741-\mathrm{y}$

(c) Society of General Internal Medicine 2018

\section{INTRODUCTION}

Thirty-three states and the District of Columbia have legalized marijuana for medical and/or recreational use. ${ }^{1}$ US adults are now less likely to perceive marijuana as risky, and more than 1 in 3 Americans believe that smoking one marijuana joint a day is much safer or somewhat safer than smoking one cigarette a day. ${ }^{1}$ These attitudes are concerning given the connection between decreased perceived risk and increased use ${ }^{2}$ and the lack of data available on the long-term health effects of marijuana use $\mathrm{e}^{3}$ and the safety of its use in various forms. ${ }^{4}$ While other national surveys assess perceived risks, there is no data about perceived safety or differences in attitudes towards marijuana's different forms. We examined the US adult population's perceptions of the comparative safety of different forms of marijuana use.

\section{METHODS}

We developed survey questions to capture perceptions of safety of marijuana's different forms among US adults. We chose the term "safety" rather than "risk," because marijuana is increasingly marketed as a relatively benign and/or herbal drug. ${ }^{5}$ The public may believe that marijuana use is harmless, and a more neutral term could allow assessment of such views. We ascertained perceptions of safety with the following question: "In your opinion, what is the safest way to use marijuana?" Response options were as follows: (a) "Smoking," (b) "Vaping bud," (c) "Vaping concentrate or liquid," (d) "Edibles," (e) "Dabbing concentrate," (f) "There is no safe way to use marijuana," and (g) "Refused." We surveyed a total of 16,260 US adults aged 18 years or older using GfK's Knowledge Panel, an online panel that reflects a probability-based, nationally representative population of US adults. The survey was administered from September 2017 to October 2017. We report on the proportion of US adults who agreed with a particular statement. Responses were weighted using weights provided by GfK to approximate the US population. We stratified viewpoints by participants' sociodemographic characteristics and the status of marijuana legalization in their state of residence. Details on survey development and administration were previously published. ${ }^{1}$

\section{RESULTS}

The response rate was $56.3 \% \quad(N=9003)$. Sociodemographic characteristics, including age, gender, and race, reflected the characteristics of the US population (Table 1). ${ }^{1}$ Overall, $52.6 \%$ of US adults believe there is no safe way to use marijuana (Table 2). Among US adults, $24.5 \%$ believe edibles are the safest way to use marijuana; $15.6 \%$ believe smoking is the safest; $3.3 \%$ believe vaping bud is the safest; $2.6 \%$ believe vaping concentrate or liquid is the safest; and $0.5 \%$ believe dabbing concentrate is the safest. Residents of recreational states and young male US adults were more likely to believe there is a safe way to use marijuana.

\section{DISCUSSION}

Almost half of US adults endorse a form of marijuana as safe to use. These beliefs are not supported by existing evidence and raise the possibility of increasing use despite gaps in knowledge about marijuana's health effects. While edible marijuana is perceived as the safest form of use by US adults, there is minimal data on the safety of any form of marijuana. ${ }^{7}$ While there is some

Published online December 10, 2018 
Table 1 Characteristics of Survey Participants, US Adults 18 and Older $(N=9003)$

\begin{tabular}{ll}
\hline \hline & $N(\%)$ \\
\hline Age (years) & \\
18-34 & $2542(28)$ \\
$35-49$ & $2172(24)$ \\
$50-64$ & $2466(27)$ \\
$\geq 65$ & $1822(20)$ \\
Gender & \\
Male & $4325(48)$ \\
Female & $4678(52)$ \\
Race & \\
Black & $1067(12)$ \\
Hispanic & $1430(16)$ \\
Other & $734(8)$ \\
White & $5772(64)$ \\
Education & \\
High school or less & $3574(40)$ \\
Some college & $2579(29)$ \\
Bachelor's degree or higher & $2850(32)$ \\
Annual household income & \\
\&20,000 & $1074(12)$ \\
\$20,000-49,999 & $2075(23)$ \\
\$50,000-74,999 & $1567(17)$ \\
Z\$5,000 & $4287(48)$ \\
Employment status & \\
Not working & $3424(38)$ \\
Working & $5579(62)$ \\
Status of marijuana legalization in state of residence & \\
Recreational & $1876(21)$ \\
Medical & $3858(43)$ \\
Non-legal & $3269(36)$ \\
Reason for marijuana use & \\
Medical & $134(11)$ \\
Recreational & $676(53)$ \\
Both & $458(36)$ \\
\hline
\end{tabular}

limited evidence that cannabinoids are beneficial for the treatment of certain medical conditions (e.g., nausea and vomiting associated with chemotherapy or pain and spasticity of multiple sclerosis), data on risks is limited and outpaced by rapid commercialization and legalization. In addition, as marijuana is still classified as a schedule 1 drug, few trials have examined the safety and efficacy of cannabinoids. Existing trials generally use pharmaceutical forms with lower doses of THC, which are not representative of most commercial marijuana products on the market today. ${ }^{6}$ Therefore, there is little data available on the safety of products marketed to the public.

Our study has several limitations. Use of an online survey may limit generalizability; however, our study population was similar in baseline sociodemographic characteristics to the populations of other federal surveys and is representative of the adult US population. ${ }^{1}$ Additionally, we did not conduct reliability testing of the questions regarding opinions on forms of use, and the phrasing of the questions may have impacted interpretation by the respondents.

As more states legalize recreational use of marijuana, further research assessing the safety of marijuana across its various forms is necessary to inform state regulations and public policy.

Table 2 Characteristics Associated with Perceptions of Safest Form for Marijuana Use

\begin{tabular}{|c|c|c|c|c|c|c|}
\hline \multirow[t]{2}{*}{ Characteristic* } & \multirow{2}{*}{$\begin{array}{l}\text { Smoking } \\
\begin{array}{l}N=1226 \\
(\%)\end{array}\end{array}$} & \multirow{2}{*}{$\begin{array}{l}\begin{array}{l}\text { Vaping } \\
\text { bud }\end{array} \\
N=279 \\
(\%)\end{array}$} & \multirow{2}{*}{$\begin{array}{l}\text { Vaping concentrate or } \\
\text { liquid } \\
N=230 \\
(\%)\end{array}$} & \multirow{2}{*}{$\begin{array}{l}\text { Edibles } \\
N=2440 \\
(\%)\end{array}$} & \multirow{2}{*}{$\begin{array}{l}\text { Dabbing } \\
\text { concentrate } \\
N=40 \\
(\%)\end{array}$} & \multirow{2}{*}{$\begin{array}{l}\text { There is no safe way to use } \\
\text { marijuana } \\
N=4704 \\
(\%)\end{array}$} \\
\hline & & & & & & \\
\hline $\begin{array}{l}\text { Total US } \\
\text { population } \\
\text { Age (years) }\end{array}$ & 15.6 & 3.3 & 2.6 & 24.5 & 0.5 & 52.6 \\
\hline $18-34$ & 19.2 & 5.4 & 2.8 & 26.6 & 0.9 & 44.2 \\
\hline $35-49$ & 16.6 & 3.3 & 3.3 & 25.9 & 0.4 & 49.6 \\
\hline $50-64$ & 15.8 & 2.3 & 2.4 & 25.7 & 0.3 & 52.6 \\
\hline \multirow{2}{*}{\multicolumn{7}{|c|}{ Gender }} \\
\hline & & & & & & \\
\hline Male & 16.3 & 3.5 & 2.6 & 25.8 & 0.5 & 50.2 \\
\hline Female & 14.9 & 3.2 & 2.6 & 23.3 & 0.5 & 54.8 \\
\hline \multicolumn{7}{|l|}{ Race } \\
\hline White & 13.6 & 3.4 & 2.4 & 27.4 & 0.7 & 51.8 \\
\hline Black & 26.3 & 1.4 & 3.1 & 13.9 & 0.3 & 54.1 \\
\hline Hispanic & 18.6 & 4.9 & 3.2 & 20.9 & 0.2 & 50.6 \\
\hline Other & 9.8 & 2.5 & 1.9 & 23.7 & 0.0 & 60.9 \\
\hline \multicolumn{7}{|c|}{ Status of marijuana legalization in state of residence } \\
\hline Recreational & 14.3 & 4.4 & 2.6 & 30.2 & 0.3 & 47.4 \\
\hline Medical & 15.0 & 3.2 & 2.9 & 24.2 & 0.5 & 53.4 \\
\hline Non-Legal & 16.9 & 2.8 & 2.2 & 21.5 & 0.6 & 54.7 \\
\hline
\end{tabular}

*Numbers are unweighted. Percentages are weighted to approximate the US population

We ascertained perceptions of safety with the following question: "In your opinion, what is the safest way to use marijuana?" Response options were as follows: (a) "Smoking," (b) "Vaping bud," (c) "Vaping concentrate or liquid," (d) "Edibles," (e) "Dabbing concentrate," (f) "There is no safe way to use marijuana," and (g) "Refused" 
Funding/Support: This research was supported in part by the National Heart, Lung, and Blood Institute of the National Institutes of Health under grant number R01HL130484-01A1. Dr. Keyhani's administrative funds provided by the Veterans Health Research Institute (NCIRE) also supported this research. Dr. Ishida was supported by a career development award from the National Institute of Diabetes and Digestive and Kidney Diseases (K23DK103963).

Role of the Funder/Sponsor: The funders had no role in the analysis and interpretation of the data; preparation, review, or approval of the manuscript; and decision to submit the manuscript for publication.

Corresponding Author: Salomeh Keyhani, MD MPH; General Internal Medicine, San Francisco Veterans Administration, San Francisco, CA, USA (e-mail: salomeh.keyhani@ucsf.edu).

Author Contributions Dr. Keyhani had full access to all the data in the study and takes responsibility for the integrity of the data and the accuracy of the data analysis. Study concept and design: Keyhani, Yoo, Dollinger, Steigerwald, and Cohen. Acquisition, analysis, or interpretation of data: Keyhani, Yoo, Dollinger, Vali, Steigerwald, Cohen, Ishida, and Vali. Drafting of the manuscript: Yoo and Dollinger. Critical revision of the manuscript for important intellectual content: Keyhani, Yoo, Dollinger, Steigerwald, Cohen, and Ishida. Statistical analysis: Vali. Obtained funding: Keyhani. Administrative, technical. or material support: Yoo, Dollinger, Steigerwald, and Vali. Supervision: Keyhani.

\section{Compliance with Ethical Standards:}

Conflict of Interest: The authors declare that they do not have a conflict of interest.

\section{REFERENCES}

1. Keyhani S, Steigerwald S, Ishida J, Vali M, Cerda M, Hasin D, Dollinger C, Yoo SR, Cohen BE. Risks and Benefits of Marijuana Use: A National Survey of US Adults. Ann Intern Med. 2018;169:282-290. https://doi.org/ 10.7326/M18-0810.

2. Keyes KM, Schulenberg JE, O'Malley PM, et al. The social norms of birth cohorts and adolescent marijuana use in the United States, 1976-2007. Addiction. 2011;106(10):1790-1800.

3. Ravi D, Ghasemiesfe M, Korenstein D, Cascino T, Keyhani S. Associations between marijuana use and cardiovascular risk factors and outcomes: a systematic review. Ann Intern Med. 2018;168:187-194.

4. Whiting PF, Wolff RF, Deshpande S, Di Nisio M, Duffy S, Hernandez AV, et al. Cannabinoids for Medical Use: A Systematic Review and Metaanalysis. JAMA. 2015;313(24):2456-2473.

5. Loria K. 23 Health Benefits of Marijuana. http://www.businessinsider. com/health-benefits-of-medical-marijuana-2014-4/\#it-can-be-used-totreat-glaucoma-1. Published March 7, 2018. Accessed October 19, 2018.

6. Steigerwald $\mathbf{S}$, Wong PO, Khorasani A, Keyhani $\mathbf{S}$. The form and content of cannabis products in the United States. $J$ Gen Intern Med. 2018;33:1426. https://doi.org/10.1007/s11606-018-4480-0. 